\title{
Pedagogical conditions for successful distance learning of foreign students: research results
}

\author{
Lyudmila Veretennikova $^{1 *}$, and Galina Dugina $^{2}$
}

${ }^{1}$ Moscow Pedagogical State University, 1/1 Malaya Pirogovskaya Str., Moscow, 119991, Russia
${ }^{2}$ Moscow City University, 5B Malyj Kazennyj pereulok, Moscow, 105064, Russian Federation

Abstract. The article focuses on the study of foreign students' subjective satisfaction with the results of their education using a video conference. The educational subject is Russian as foreign language. The attitude of students to video lectures was studied using an online questionnaire. The purpose of the study is to assess the methods of organizing video sessions. The study confirmed the general trend towards a decrease in students' interest in distance learning. According to studies' results it was stated the pedagogical conditions to ensure satisfaction with video lessons at a sufficient level. To maintain interest in a video lesson, we suggest preparing basic materials and materials for self-study. All texts should be converted to electronic format and placed in special repositories. During the video lesson, it is recommended to alternate activities (listening, speaking, writing, reading) and visualization. Although videoclips, pictures and presentations were received favorably by students it was pointed a decline in interest to these training facilities. It is suggested to record planned and spontaneous explanations in video recordings and text. The results of the study have been applied in educational process for Russian students.

\section{Introduction}

The need to study the features of distance learning (video lessons) is induced to the practical need to change the teaching methodology when it was switching to distance learning in Russia (April 2020). The transfer of the traditional scheme of teaching Russian as a foreign language to e-learning format has shown that the quality of such an educational process has been declining, and foreign students have expressed subjective dissatisfaction. A large number of studies are devoted to the distance learning both in Russian and foreign pedagogical science (Abramova E. N., Bekhterev A. N., Bogolyubov V. I., Kalinina A. I., Loginova A.V., Mamed M. A., Timofeeva O. Yu., Tolokonnikov S. V., Mayer Richard E., Heiser J., Lonn S., etc.). However, methodological and practical aspects of choosing the structure of video lessons, selecting means for training via video conferencing in comparison with face-to-face training need further study.

\footnotetext{
*Corresponding author: lk.veretennikova@mpgu.su
} 


\section{Methods and results}

Scientific base of research is the principle of culture-based approaches in learning of foreign languages [1]; the thesis on the need to develop the creative potential of students [2]; the thesis on self-awareness of their own characteristics and readiness to develop their creative potential [3]; the principle of providing creative situations for personal selfrealization [4]; the principle of pedagogical co-creation, creative cooperation in collective activity [4]; the thesis on the development of the ability to generate new non-standard ideas [5]; the thesis on the need to understand the contradiction between the problem and the method of its solution that has not yet been found [6].

The purpose of the study is to assess the methodology of organizing video lessons by students, to track the decrease in interest of foreign students in the study of Russian as a foreign language, and to correct the identified shortcomings in the distance technologies used.

During the survey, the method of continuous questioning was used. Statistical data processing was performed using the $\mathrm{R}$ programming language for statistical data analysis (version 4.0.1).

The survey in the form of an online questionnaire (the Microsoft Teams platform) was conducted in two stages: at the beginning of the mass transition to distance learning (April 2020) and at the end of the semester (June 2020). 25 foreign students were interviewed. At the moment of study respondents were in Russia, China, and Taiwan.

The questionnaire consisted of nine questions (in Russian) with the ability to choose several answers. Comparing the distribution of responses to the first question of the questionnaire "Are you always interested in distance learning?" at the first and second stages of the study, we noted a decrease in the number of "Yes" responses from $60 \%$ to $48 \%$. This is due to the general fatigue of students by the end of the semester as well as the fact that the program of study, the topics of the classes did not always meet the expectations of students.

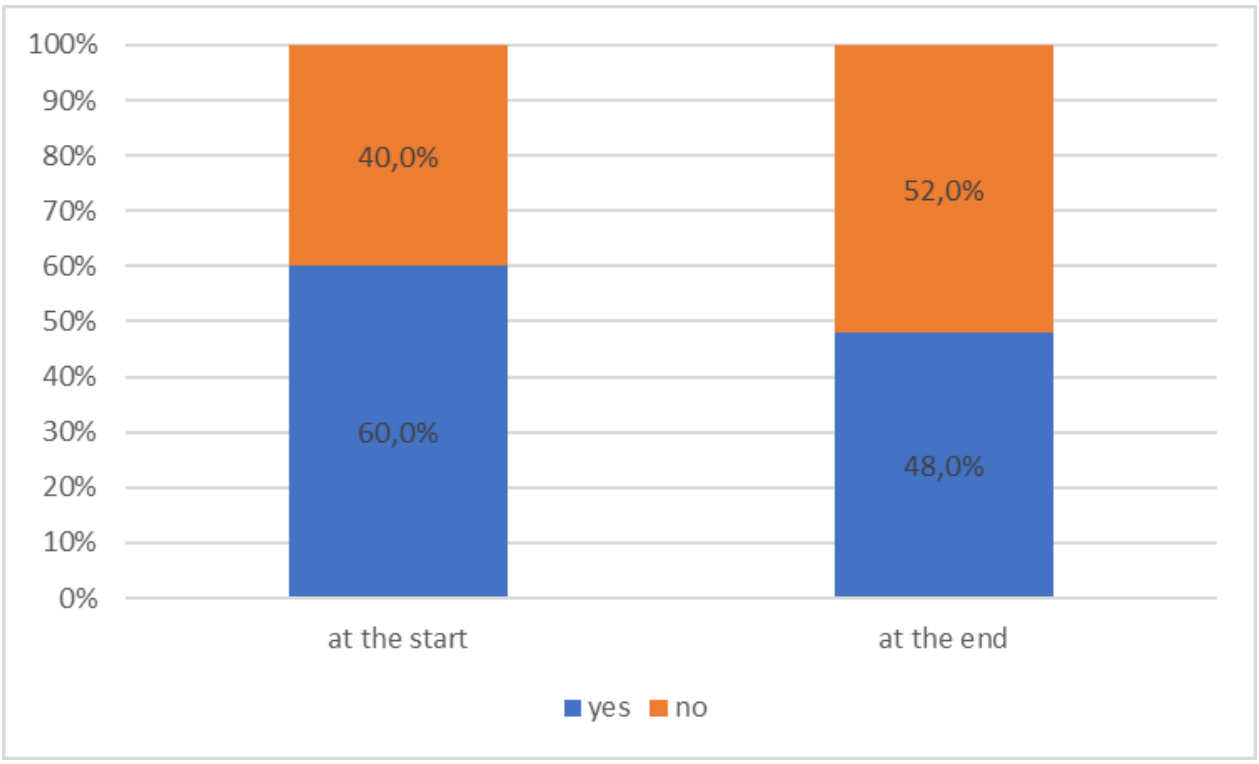

Fig. 1. The distribution of answers to the question "Are you always interested in distance learning?"

The following questions showed under what conditions the video lessons were interesting and under what condition they were not. For the second question, "What do you like in distance classes?" at the beginning of the study the majority of students were 
attracted by the availability of educational materials that were loaded for the lesson (68\%). At the end of the study many students liked the fact that they could study in any convenient place $(84 \%)$. The change in preferences may be due to the move of most foreign students to their home country (China or Taiwan).

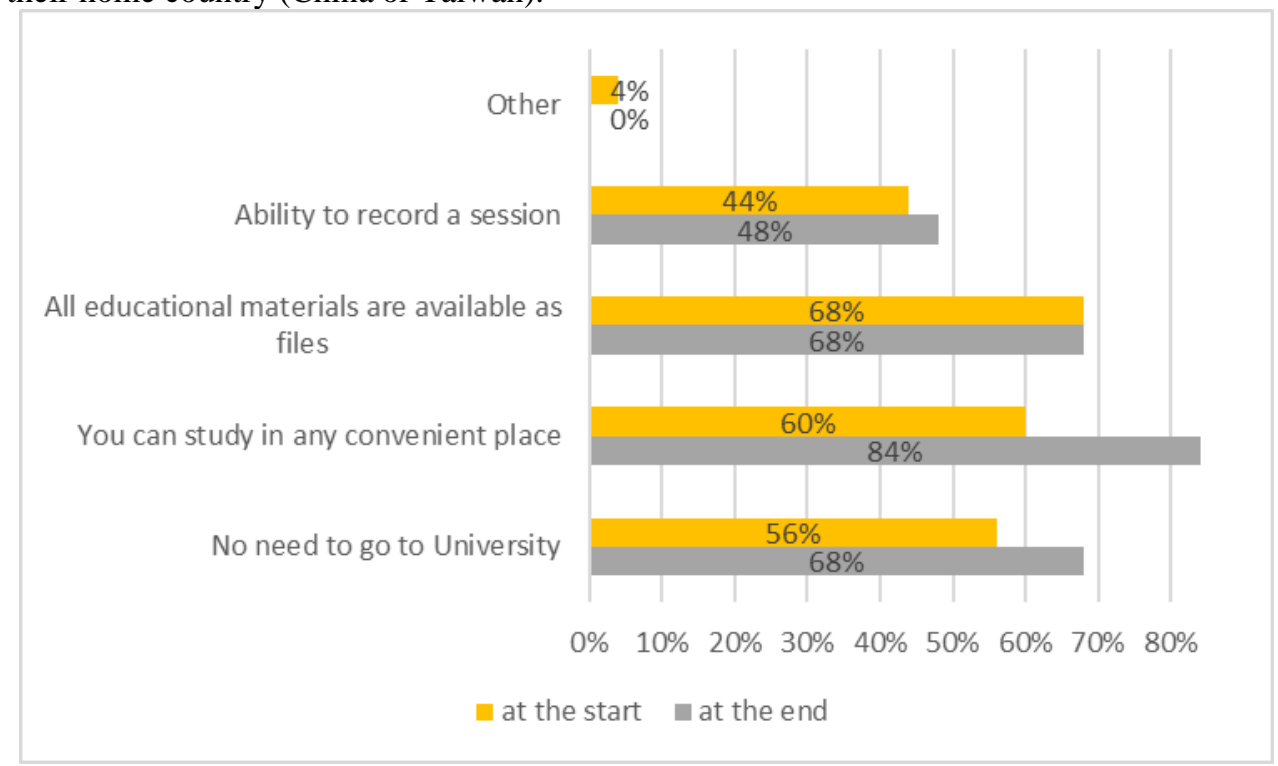

Fig. 2. The distribution of answers to the question "What do you like in distance classes?"

The main reasons for dissatisfaction with distance learning are reflected in the third question of the questionnaire - "What do you not like about distance learning?". At the beginning and at the end of the study, the answers were almost identical: students were not satisfied with the poor quality of communication ( $72 \%, 72 \%$ respectively), the schedule and time of classes $(36 \%, 32 \%)$.

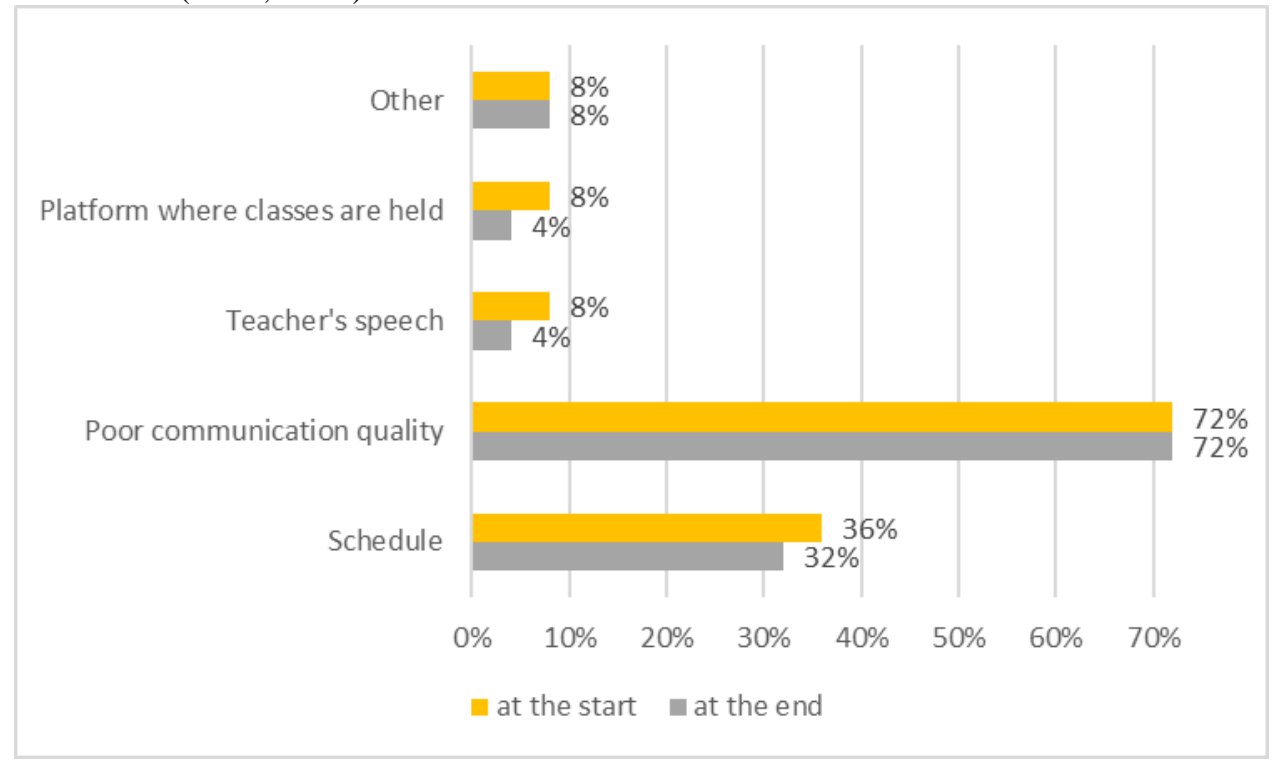

Fig. 3. The distribution of answers to the question "What do you not like in distance classes?"

Using the fourth question of the questionnaire, we found out what is missing in the distance lesson. At the beginning of the study the majority of students noted lack of 
visibility (52\%) and lack of dynamism (36\%). At the end of the study the students' opinion changed: the number of choices for the answer "lack of dynamics" (52\%) and "lack of interesting topics for discussion" (36\%) increased. This means that an increase in the share of visual materials during the course (presentations, video clips, audio) led to an oversaturation and a desire for live (face-to-face) communication with the teacher, which was impossible.

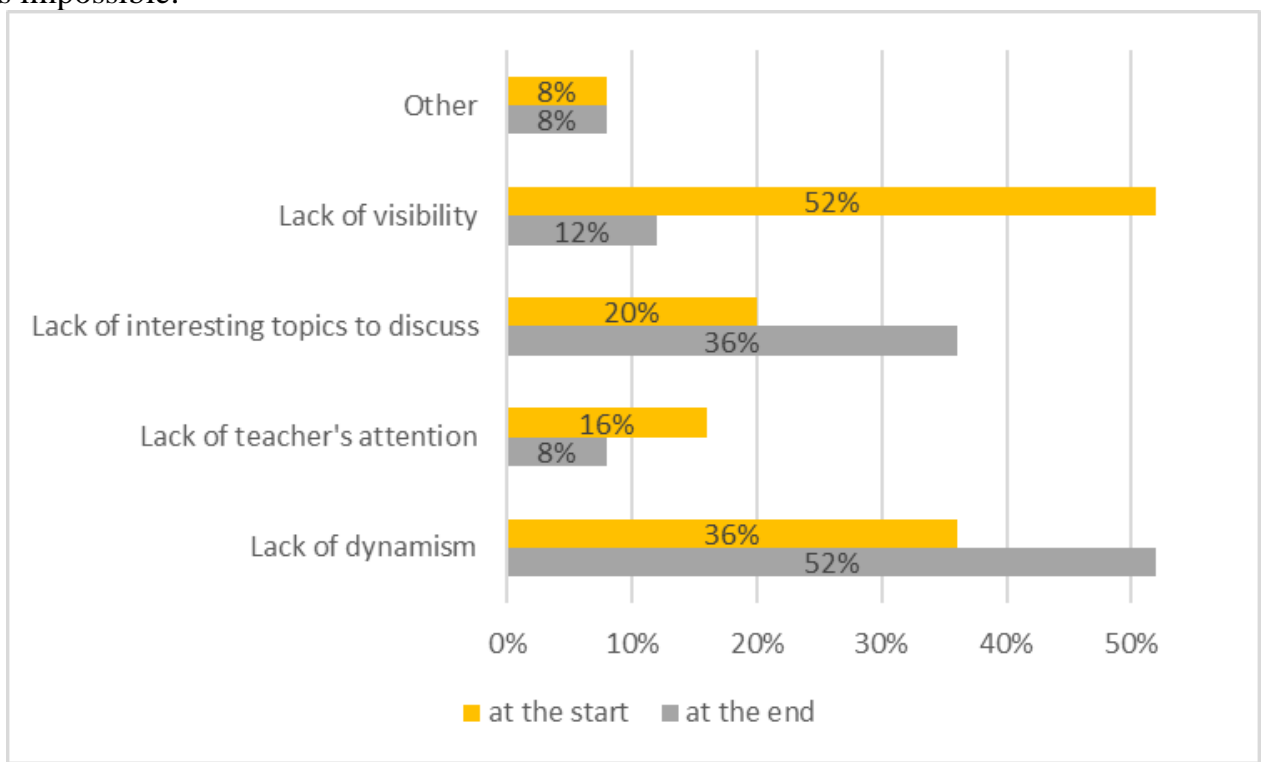

Fig. 4. Distribution of answers to the question "What is missing in distance classes?"

When evaluating interesting points in distance learning in Russian as a foreign language (the 5th question of the questionnaire), the majority of students at the beginning and at the end of the study chose to read texts on various topics (72\%, $64 \%$ ), to watch video clips (68 $\%, 72 \%)$ and to learn from a native speaker $(60 \%, 48 \%)$. 
The need to speak only Russian

Opportunity to learn from a native speaker

Watching videos

Reading texts on various topics

Performing various tasks
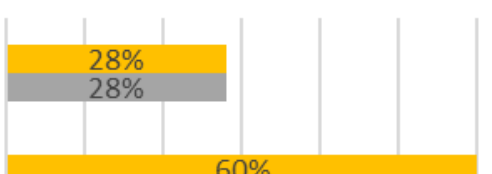

$48 \%$

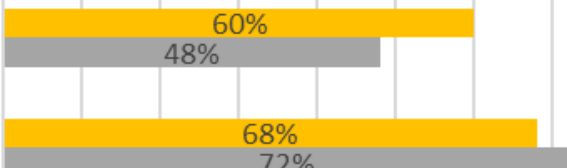

$72 \%$

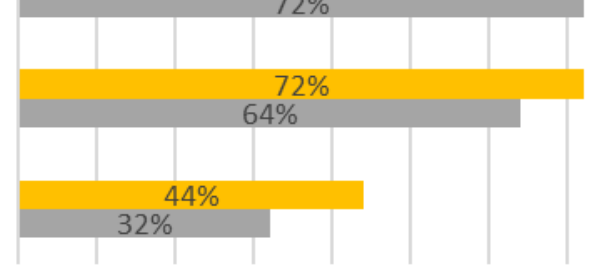

$\begin{array}{llllllll}0 \% & 10 \% & 20 \% & 30 \% & 40 \% & 50 \% & 60 \% & 70 \%\end{array}$

at the start $\quad$ at the end

Fig. 5. The distribution of answers to the question "What of the following are you interested in online classes of Russian as a foreign language?"

The 6th question showed what form the information should be presented in so that students can easily remember it. At the beginning of the semester, students noted that they need presentations (40\%) and teacher's explanations, accompanied by visualization of the material (20\%). At the end of the study, students' preferences have differed: the majority of respondents chose the teacher's explanations (44\%), while the percentage of students who chose presentations and information in the form of small texts decreased to $24 \%$ and $16 \%$, respectively. At the significance level $\alpha=0.05$ according to the Fisher criterion ( $\mathrm{p}$-value $=$ $0.004693)$, these differences were statistically significant. Differences in responses can be attributed to the specifics of transmitting oral and visual information during video conferencing.

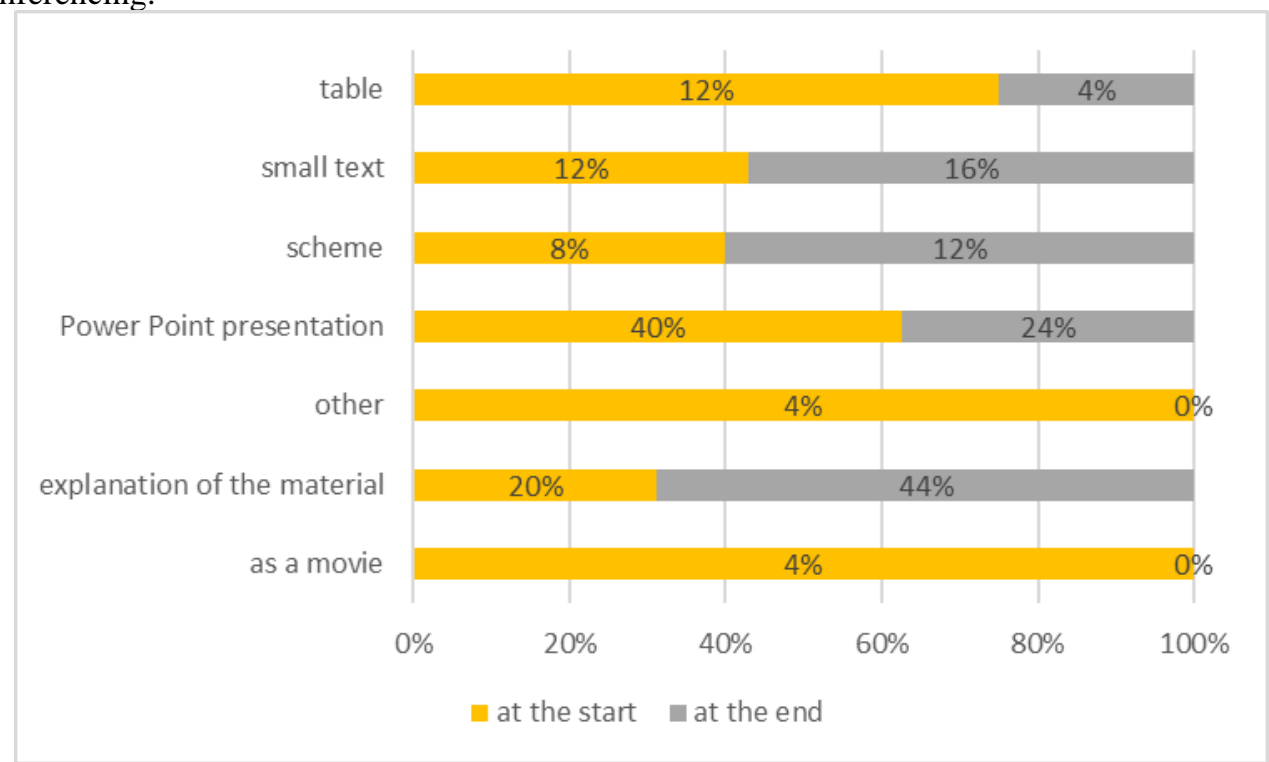

Fig. 6. The distribution of answers to the question "In what form shall I present information so that you can easily remember it?" 
Both at the beginning and at the end of the semester, the majority of students preferred tests as a form of knowledge control $(52 \%, 56 \%)$. Readiness to complete tasks has been halved (from $32 \%$ to $16 \%$ ).

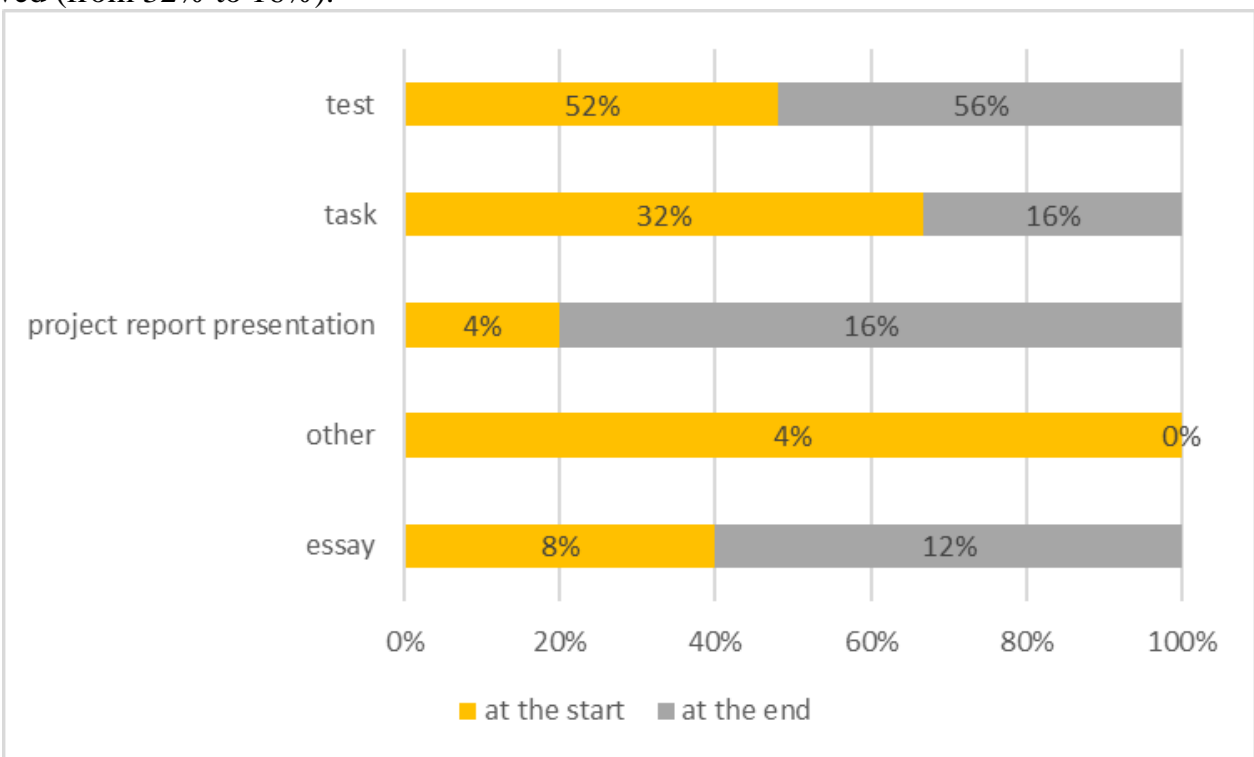

Fig. 7. The distribution of answers to the question "In what form should tests be so that you are comfortable performing them?"

The vast majority of respondents indicated that they were satisfied with the lesson when "everything they hear is clear" (92\%, $96 \%)$. But the percentage of students who enjoyed "fun and interesting activities" decreased from $80 \%$ to $68 \%$.

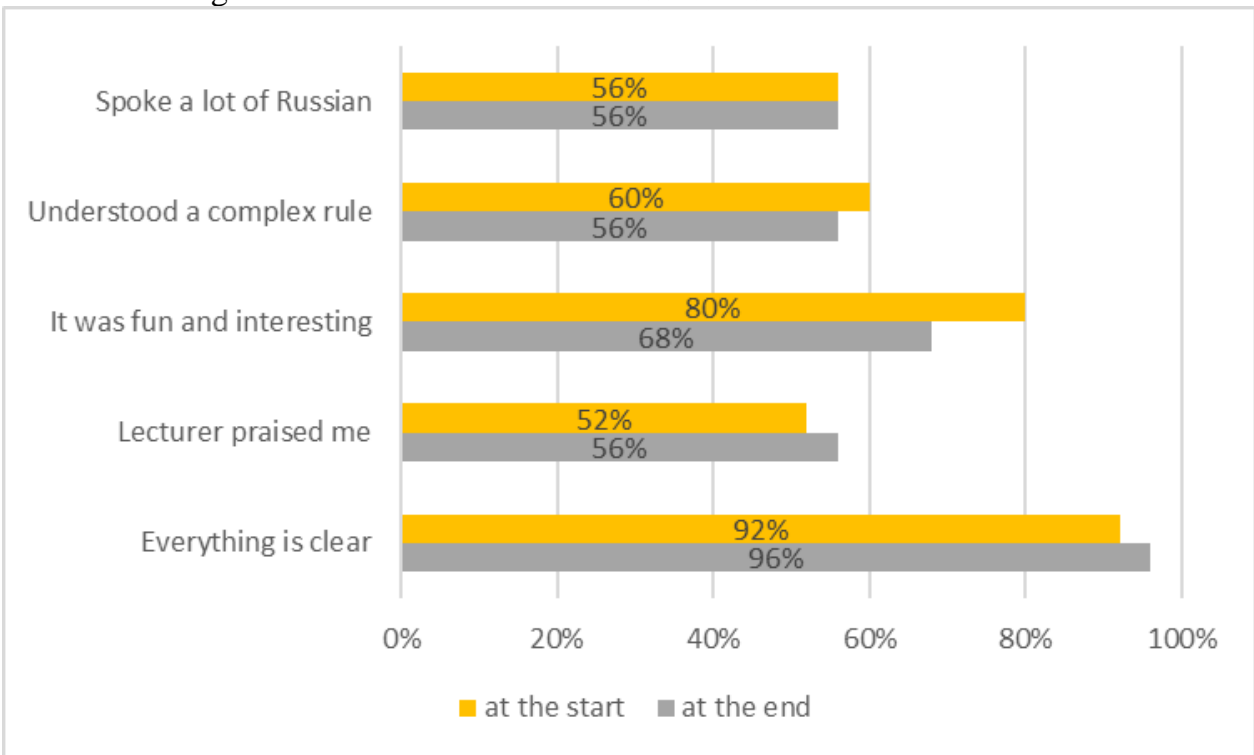

Fig. 8. Distribution of answers to the question "When do you enjoy remote lessons in Russian as a foreign language?"

During the semester, the proportion of students who noted the need to improve the technical and organizational component of distance learning increased 2 times. These changes are most likely related to the departure of some students abroad. 


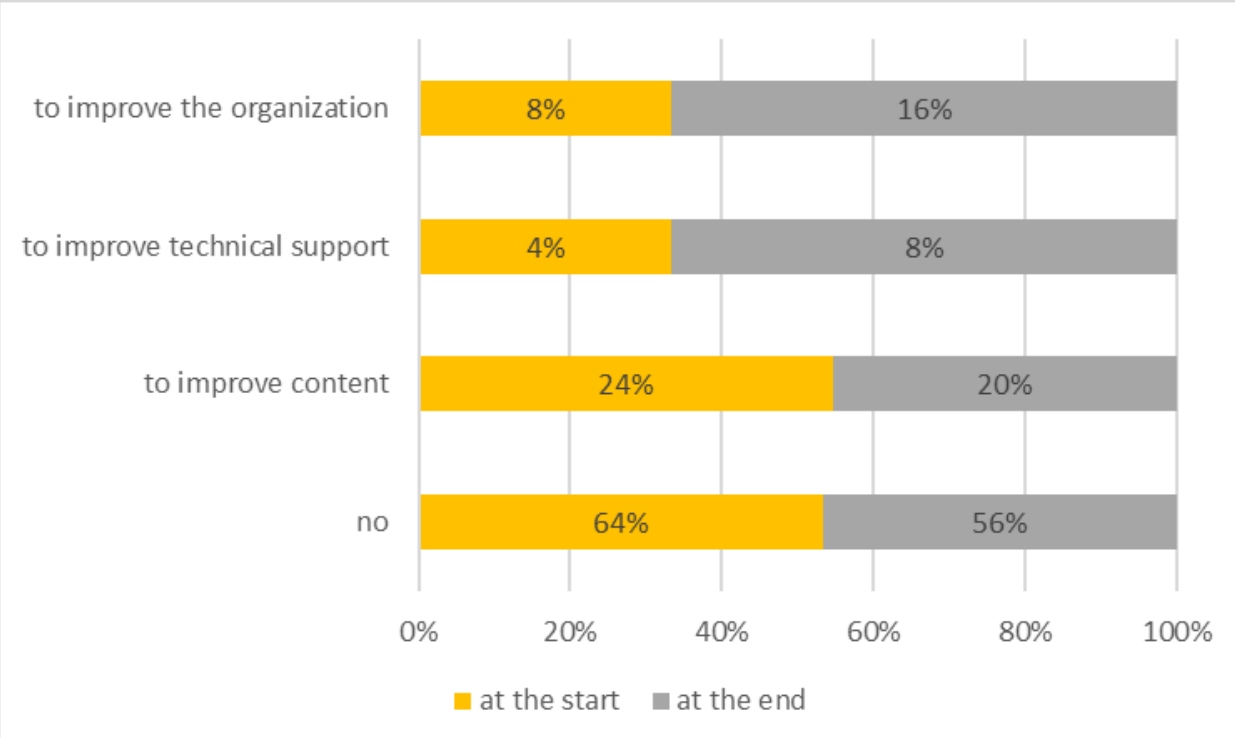

Fig. 9. Distribution of answers to the question "What are your suggestions for conducting remote classes in Russian as a foreign language?"

Our study confirmed the general trend towards a decrease in students' interest in distance learning but gave us the opportunity to determine the pedagogical conditions that allow to maintain satisfaction with this form of education at a sufficient level.

\section{Conclusion}

We will formulate conclusions in the form of recommendations to a teacher of Russian as a foreign language:

- we advise you to prepare basic and additional (for self-study) materials;

- convert all texts to electronic format and place them in special repositories;

- regularly alternate activities (listening, speaking, writing, reading), visualization;

- think of ways to record explanations and save the lesson information.

The data obtained in the study gives teachers a reason to think about changing the methodology of distance learning.

\section{Acknowledgments}

This paper was financially supported by the Russian Foundation for Basic Research, grant № 20-012-22046.

\section{References}

1. E. G. Tareva. Yazyk i kultura, 40, 302-320, (2017) (in Russ.)

2. G. A. Uskova, PhD thesis, (2005) (in Russ.)

3. L. K. Veretennikova, G. A. Uskova, textbook, Moscow, (2008) (in Russ.)

4. L. K. Veretennikova, monograph, Moscow, (2019) (in Russ.)

5. L. K. Veretennikova, monograph, Moscow, (2018) (in Russ.)

6. L. K. Veretennikova, N. N. Sotnikova, \& G. A. Uskova, monograph, Stavropol, (2006) (in Russ.) 